\title{
Effects of Intensification of Vaporization by Decompression to the Vacuum (IVDV) and frying on physicochemical, structural, thermal, and rheological properties of chickpea (Cicer arietinum $\mathrm{L}$. ) powder
}

\author{
Husnain RAZA ${ }^{1,2,3 *}$ (D), Kashif AMEER ${ }^{4,5}$, Farah ZAABOUL ${ }^{2,3}$, Muhammad SHOAIB $^{2,3}$, Imran PASHA ${ }^{6}$, \\ Muhammad NADEEM ${ }^{7}$, Xiaofeng REN ${ }^{1}$, Lianfu ZHANG ${ }^{2,3,8,9}$
}

\begin{abstract}
Hard textural attributes of chickpea necessitate the employment of specialized pretreatment prior to roasting. As compared to frying, the Intensification of Vaporization by Decompression to the Vacuum (IVDV) as a vacuum expansion (VE) technique was utilized to improve and preserve the nutritional, textural, and structural properties of chickpeas. It was clearly demonstrated that frying (FR) caused decrease in degrees of lightness in chickpeas as compared to VE samples. Raw and VE samples showed a combination of green and red colors. VE caused $\mathrm{C}=\mathrm{O}$ stretching in chickpeas and imparted desirable color. The surface fissures were more evident in FR grains as compared to VE grains. The grain structure was modified from largely ovoid to round or spherical forms. Enhanced cross-linking was observed in VE samples due to stable rheological properties. IVDV improved nutritional, color and structural attributes of chickpeas were preserved after texturization.
\end{abstract}

Keywords: chickpea; vacuum expansion; frying; viscosity; microstructure; FTIR, XRD.

Practical Application: IVDV can be exploited for chickpea roasting.

\section{Introduction}

Among legumes of the Fabaceae family, chickpea (Cicer arietinum L.) is popular among conscious consumers and is used as one of the trivial and widely consumed legumes around the globe (especially in the Mediterranean plains) in the form of roasted snack products (Zhong et al., 2018; Mrad et al., 2015). The roasting process is employed to bring about the formation of internal pores in chickpeas structure; however, until now, the conventional roasting process does not produce the desirable features of crunchiness, which is the most premium and peculiar characteristic with regard to consumers' likeness and desirability (Mrad et al., 2014; Ladjal-Ettoumi et al., 2016). Moreover, the color, texture, and crunchy behavior of roasted foodstuffs, including chickpeas, has been recognized as the most significant factor to determine palatability and easting quality of roasted chickpeas. The main hindrance in the attainment of the desired crunchiness is reported to be the formation of the hard texture of chickpea grains during cooking at the initial level (Mrad et al., 2015; Petitot et al., 2010). Furthermore, the enhanced thermal processing at elevated temperatures may lead to deteriorative quality effects, primarily on texture and color (Mrad et al., 2015;
Ladjal-Ettoumi et al., 2016). High-temperature treatment may also cause thermal degradation or modifications in phenolic compounds contents, and this becomes more pertinent in the case of chickpeas because of rich phenolic profiles of chickpeas (Ladjal-Ettoumi et al., 2016; D'Archivio et al., 2010).

Recently, a newly emerged process, known as IVDV (Intensification of Vaporization by Decompression to the Vacuum), has been reported to be more effective as compared to DIC as texturizing pretreatment (Mrad et al., 2014; Louka \& Allaf, 2004). In comparison with DIC, IVDV is differentiated owing to the fact that in IVDV, the compression to elevated pressure (up to 15 bars) is achieved in less than $1 \mathrm{~s}$, while DIC requires $10 \mathrm{~s}$ of the time period to reach the required level of elevated pressure (Mrad et al., 2015). The most advantageous feature offered by this rapid compression consists of potential possibility regarding the treatment of thermo-sensitive food products involving treatment time of less than a few seconds under high pressure and does not possess enough withstanding ability at an extended time period of more than a few seconds. IVDV technique provides an excellent opportunity as a potential pretreatment method to bring the modification 
of structural features of raw chickpeas to prepare them for further unit operations or treatments (Mrad et al., 2014, 2015). The purpose of this study was to understand the effects of IVDV and frying on physicochemical, structure, thermal and rheological properties of chickpea to find a suitable texturizing pretreatment for industrial post-processing with improved functionality of chickpea powder obtained after different texturizing pretreatments, such as frying and IVDV as compared to untreated (control) samples.

\section{Materials and methods}

\subsection{Raw materials}

Chickpeas were provided by Xinjiang Tian Shan Qi Dou Biotechnology Co. Ltd. The sample was collected from a single lot $(20 \mathrm{~kg})$ and stored at room temperature $\left(25 \pm 2{ }^{\circ} \mathrm{C}\right)$ in polyethylene terephthalate (PET) containers before use.

\subsection{Sample pretreatment}

Chickpeas were rehydrated with distilled water at room temperature. Conditioned chickpeas were then stored in tight PVC bags at $4{ }^{\circ} \mathrm{C}$ for 1-2 days to obtain uniform redistribution of water until further use.

\subsection{Sample processing for IVDV}

The experimental setup for the IVDV process is shown in Figure 1. It is composed of four major components: processing chamber, steam generation system, vacuum tank, and rapid decompression valve. The rehydrated and homogenized chickpeas were placed in the processing chamber, where the initial vacuum was established by pressure drop from atmospheric to vacuum pressure. After this, the chickpeas were treated with high pressure (up to 15 bar) steam for a short time period of approximately 1-200 s. The final process stage included instant pressure release towards vacuum at approximately $1 \mathrm{mbar}$. Finally, the chickpeas were rehydrated in an oven at $50^{\circ} \mathrm{C}$ for $24 \mathrm{~h}$ followed by roasting at $200{ }^{\circ} \mathrm{C}$ for $6 \mathrm{~min}$ using an electric seed roasting machine.

\subsection{Frying of chickpeas}

Chickpeas were soaked overnight within a beaker using distilled water at chickpeas to water ratio of 1:5. The soaked chickpeas were then oven-dried at $50{ }^{\circ} \mathrm{C}$ for $24 \mathrm{~h}$. The frying was carried out at a medium to high temperature range using cooking oil for 6-7 min. The fried chickpeas were then cooled at room temperature and finally stored at $4{ }^{\circ} \mathrm{C}$ in polyvinyl chloride (PVC) bags until further analyses.

\subsection{Color analysis}

The color was measured using a Hunter Colorflex ${ }^{\mathrm{TM}} \mathrm{Lab}$ Calorimeter (Hunter Associates, Reston, VA). Each sample measurement was taken in triplicate, and the values were expressed as mean \pm S.D.

\subsection{Water activity measurement}

Water activity $\left(a_{w}\right)$ of extruded samples, after storage in a desiccator containing silica gel for $24-48 \mathrm{~h}$ at $24^{\circ} \mathrm{C}$, was measured by the Novasina Lab Master- $\mathrm{a}_{\mathrm{w}}$ instrument. All water activity measurements were recorded at $25^{\circ} \mathrm{C}$ (AACC, 2000).

\subsection{FTIR analysis}

The FTIR spectrum of flour was recorded by using Nicolet ${ }^{\mathrm{TM}}$ FT-IR spectrophotometer (Thermo Fisher Scientific, Massachusetts, United States). Three spectra replicates were obtained for each sample.

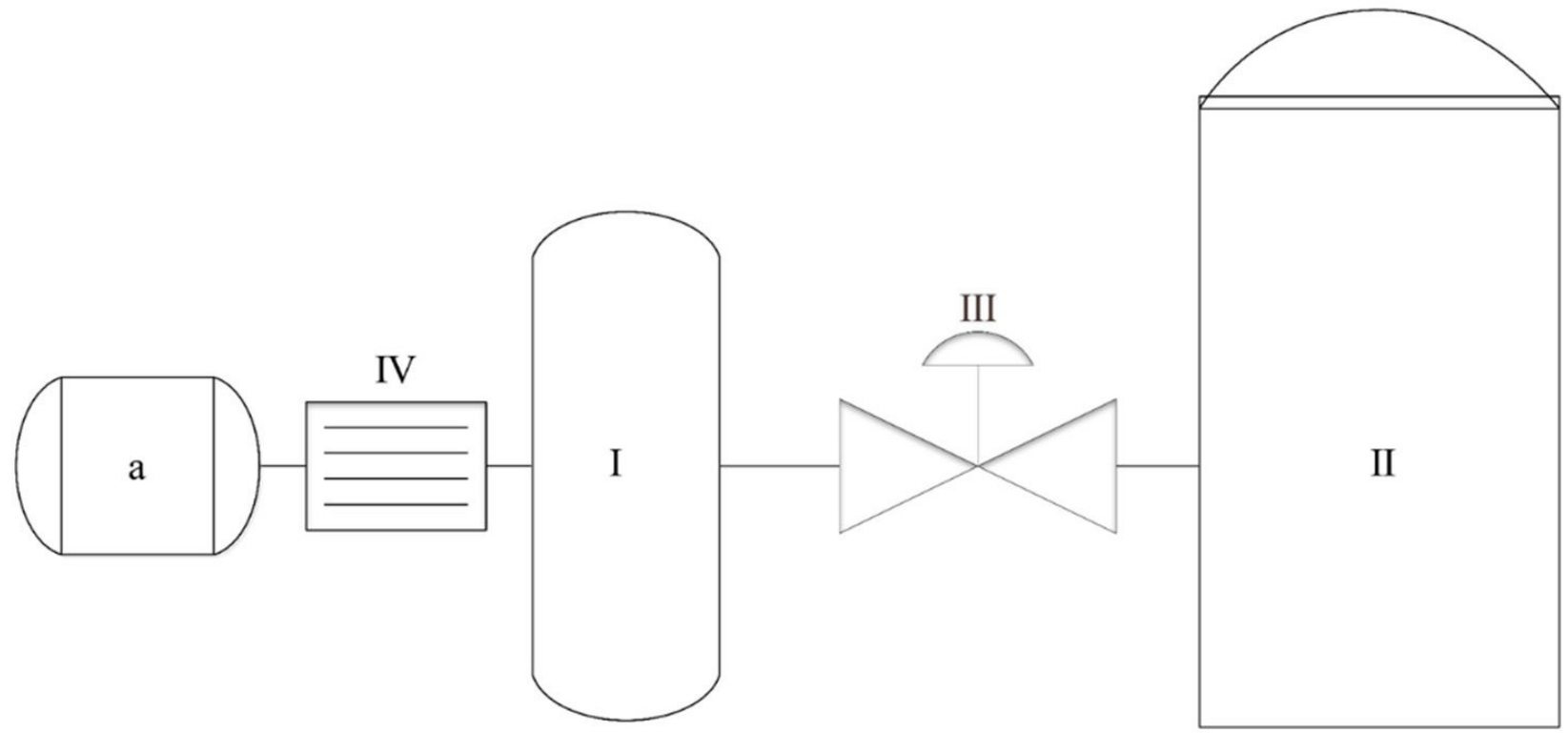

Figure 1. Schematic diagram of IVDV reactor: (I): processing chamber; (II) vacuum tank; (III): decompression valve; (IV): rapid steam generation system connected with steam buffer tank (a). 


\subsection{X-Ray Diffraction measurement}

The XRD patterns of different particle sized fried, and roasted chickpea samples were measured by Bruker's D2 PHASER analytical diffractometer (Bruker Corp. Massachusetts, USA) equipped with pixel-detector employing $\mathrm{Cu}(\mathrm{K} \alpha)$, running at $30 \mathrm{kV}$ and $10 \mathrm{~mA}$. The samples were analyzed between $2 \theta$, $5.002-75.022$ with a step interval of $0.05 \mathrm{~s}$, and $5^{\circ} / \mathrm{min}$ scan rate.

\subsection{Thermogravimetric analysis (TGA)}

Measurements of mass loss versus temperature were performed using a thermogravimetric analyzer, model TGA 2 (Mettler Toledo, Ohio, USA), under $\mathrm{N}_{2}$ purge. Typically, 3 to $5 \mathrm{mg}$ of sample was placed on a Pt pan and heated from $30{ }^{\circ} \mathrm{C}$ to $600{ }^{\circ} \mathrm{C}$ at a rate of $10^{\circ} \mathrm{C} / \mathrm{min}$.

\subsection{Scanning electron microscopy (SEM)}

The microstructure of chickpea fractions was examined through a scanning electron microscope (SEM) (JEOL, JSM-5410LV, Tokyo, Japan). Each sample was coated with gold in a sputter coater (Structure Probe, West Chester, PA) before being scanned. Particle size was measured by the instrument software. About 50 particles were chosen randomly for particle size measurement.

\subsection{Rheological parameters determination}

The dough was prepared by adding the required amount of water (flour to water ratio 1:2) in a mixer (Hobart N50 5-Quart, Canada) for $10 \mathrm{~min}$ and rested for $30 \mathrm{~min}$ before rheological measurement. Sweep experiments were performed to calculate small-amplitude oscillatory strain ranging (0.001-10\%), and the elastic (G') and viscous (G”) shear moduli, at a constant frequency of $0.1 \mathrm{~Hz}$ were monitored to determine the limit of the linear viscoelastic region. Following an initial equilibration of samples for $5 \mathrm{~min}$ at $25^{\circ} \mathrm{C}$, ramp heating was carried out at $5{ }^{\circ} \mathrm{C} / \mathrm{min}$ to an endpoint of $95^{\circ} \mathrm{C}$ at a constant frequency of $1 \mathrm{~Hz}$.

\subsection{Statistical analysis}

All the experiments were repeated thrice, and measurements were recorded as mean along with standard deviation. Analysis of variance (ANOVA) and the difference between the means was performed by SPSS software (version 19.0 IBM, Armonk, NY, USA) at $p<0.05$ significance level.

\section{Results and discussion}

\subsection{Color}

The raw chickpeas sample showed an $L^{*}$-value of 90.19 , which demonstrated clearly that raw chickpeas exhibited a higher degree of lightness as compared to VE and FR chickpeas. Whereas in the case of VE-chickpeas, the $L^{\star}$-value was 83.43, and a slight decrease of $L^{*}$-value was evident of the effect of VE pretreatment on the lightness of chickpeas as compared to control (raw chickpeas). Furthermore, the effect of frying treatment was also evaluated, and $L^{*}$-value was 74.45 in the case of FR chickpeas. It was demonstrated that FR treatment had significant $(p<0.05)$ influence and led to decreases in degree of lightness in chickpeas while VE did not cause any significant effect on the lightness, and the slight decreasing tendency was observed in VE chickpeas. The results showed that a tinge of red color appearing in chickpea grains subjected to VE and FR treatments. In case of FR grains, the degree of redness was highly significant with $a^{*}$-value of 5.67, while VE caused an increase in the degree of redness (3.09) when compared with control (1.945), but this increase was relatively gradual, and a tinge of redness appeared uniformly, whereas FR caused an intensive rise in redness and was more prominent as compared to VE chickpeas and control. Control (raw) and VE chickpeas showed a mixed combination of green and red colors while the degree of greenness showed a high tendency in the case of control samples. While frying the chickpeas, Shokrollahi Yancheshmeh et al. (2018) also found a decrease in the tendency of lightness while increases in degrees of redness and yellowness.

\subsection{Water activity}

The results of water activity $\left(\mathrm{a}_{\mathrm{w}}\right)$ are given in Table 1 for all samples (control, VE, and FR chickpeas). The raw chickpeas exhibited $\mathrm{a}_{\mathrm{w}}$ of 0.33 . VE and FR pretreatments exerted their significant influence on the $\mathrm{a}_{\mathrm{w}}$ of processed chickpeas. The $\mathrm{a}_{\mathrm{w}}$ of VE samples was 0.08 , while FR samples had $0.09 \mathrm{a}_{\mathrm{w}}$. The increased $\mathrm{a}_{\mathrm{w}}$ level may lead to favorable conditions for microbial growth. Bacterial growth may initiate at the $a_{w}$ level of 0.91 , whereas fungi require $\mathrm{a}_{\mathrm{w}}$ of 0.7 for favorable growth on manufactured foodstuffs. VE caused a much lower reduction in moisture content, which lowered $\mathrm{a}_{\mathrm{w}}$ of VE chickpeas. FR also caused a reduction in $\mathrm{a}_{\mathrm{w}}$, but comparatively, the declining tendency was highly significant in VE chickpeas. In comparison with control, the VE and FR showed quite lower water activities. Hence, it could be inferred that both pretreatments were effective in ensuring microbial decontamination owing to lower $a_{w}$ than

Table 1. Color values and water activity $\left(\mathrm{a}_{\mathrm{w}}\right)$ of raw, VE and FR chickpea samples.

\begin{tabular}{ccccc}
\hline \multirow{2}{*}{ Chickpea Sample } & \multicolumn{2}{c}{ Color values } & \multirow{2}{*}{ Water activity $\left(\mathrm{a}_{\mathrm{w}}\right)$} \\
\cline { 2 - 4 } & $\mathrm{L}^{*}$ & $\mathrm{a}^{*}$ & $\mathrm{~b}^{*}$ & $0.33 \pm 0.01 \mathrm{a}$ \\
Raw & $90.19 \pm 0.48 \mathrm{a}$ & $1.95 \pm 0.09 \mathrm{a}$ & $18.50 \pm 1.69 \mathrm{a}$ & $0.08 \pm 0.00 \mathrm{~b}$ \\
VE & $83.43 \pm 0.13 \mathrm{~b}$ & $3.09 \pm 0.24 \mathrm{~b}$ & $24.58 \pm 0.15 \mathrm{~b}$ & $0.09 \pm 0.00 \mathrm{~b}$ \\
\hline FR & $74.45 \pm 0.59 \mathrm{c}$ & $5.67 \pm 0.73 \mathrm{~b}$ & $31.15 \pm 0.62 \mathrm{c}$ & 0 \\
\hline
\end{tabular}

Data are represented as the mean of three independent experiments. $L^{\star}$ : Lightness/darkness where a low number (0-50) indicates dark and a high number (51-100) indicates light. $\mathrm{a}^{\star}$ : Red/ Green Value where a positive number indicates red and a negative number indicates green. $b^{*}$ : Blue/Yellow Value where a positive number indicates yellow and a negative number indicates blue. 
control, which may be beneficial in extending the shelf life of processed chickpeas with favorable retention of sensorial, organoleptic and physicochemical characteristics. Quite lower $\mathrm{a}_{\mathrm{w}}$ values of both VE and FR indicated shelf stability of chickpeas after the application of pretreatments. Similarly, Ullah (2014) has reported $\mathrm{a}_{\mathrm{w}}$ of 0.7 for chickpea samples and also noted the positive relationship of $\mathrm{a}_{\mathrm{w}}$ during 40 days of storage period. Further increase in storage led to a significant decline in the moisture content of chickpea samples.

\subsection{FTIR spectral features}

The FTIR spectra of the control and other chickpea samples subjected to VE and FR are demonstrated in Figure 2. As evident from FTIR spectra, the three distinct peaks were observed in spectral regions of 800-1200, 1600-2000, and 2700-3300 $\mathrm{cm}^{-1}$, respectively. The shoulder band was most significant in the case of control (raw) samples at $3400 \mathrm{~cm}^{-1}$ regions as compared to VE and FR chickpea samples. The prominent shoulder band in control samples could be possibly explained in terms of the presence of primary amines in significantly $(p<0.05)$ higher quantities in comparison with VE and FR samples, whereas bands representing the primary amines were relatively weaker and broader. Usually, peak broadening is caused due to the existence of $\mathrm{O}-\mathrm{H}$ stretching owing to hydrogen bonding in functional groups. The spectral bands at the absorption region of $1650-1580 \mathrm{~cm}^{-1}$ usually indicate the presence of primary amines with a characteristic $\mathrm{N}-\mathrm{H}$ stretching of bending vibration. This band's weakening effect might be due to the influence of frying and vacuum expansion-based treatments.

The secondary amines were present in the highest concentrations in FR chickpeas, whereas the control and VE chickpeas showed the same banding patterns, and secondary amines were present in almost equivalent amounts in both VE and control samples. Other notable spectral bands were indicative of aromatic amines (C-N stretch: $\left.1335-1250 \mathrm{~cm}^{-1}\right)$, aliphatic amines (C-N: $\left.1250-1020 \mathrm{~cm}^{-1}\right)$, and primary and secondary amines only $\left(\mathrm{N}-\mathrm{H}\right.$ stretch: $\left.910-665 \mathrm{~cm}^{-1}\right)$. The banding patterns

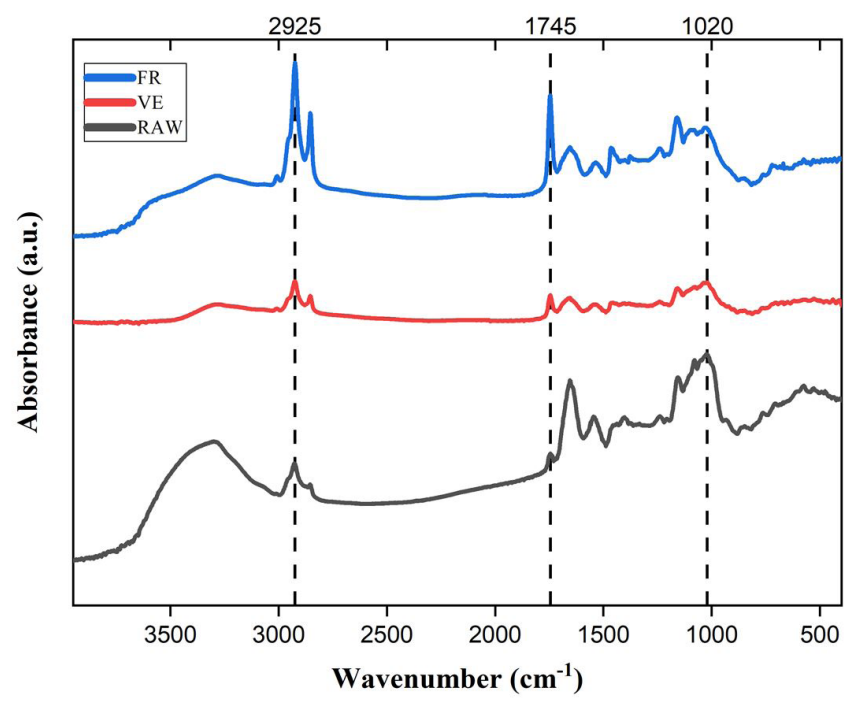

Figure 2. FTIR spectra of raw, VE and FR chickpea samples. existing in the spectral range of $1500-1800 \mathrm{~cm}^{-1}$ indicated the fingerprint regions, which were mainly ascribed to the absorption of polyphenolic compounds, and stretches of carbonyl groups $(\mathrm{C}=\mathrm{O})$ were visible at a specific spectral region of $1800 \mathrm{~cm}^{-1}$. Most Prominent $\mathrm{C}=\mathrm{O}$ stretching was found in FR chickpeas in comparison with control. The FR treatment was not so much influential in causing decreases in phenolic compounds, while $\mathrm{C}=\mathrm{O}$ stretching of VE chickpeas was less in magnitude as compared to control, which was evident from the stability of functional groups related to phenolic compounds even after exposure to vacuum expansion pretreatment. Specifically, the band in the region of $1680 \mathrm{~cm}^{-1}$ was attributed to the presence of phenols in VE samples, especially as well as in control and FR samples. Other chemical moieties and components which appeared at spectral regions of absorption bands of $1800-750 \mathrm{~cm}^{-1}$ are comprised of lipids, protein components, carbohydrates, and phenolic compounds. The curves at this particular absorption regions were quite lower in VE samples as compared to those observed in FR and control samples. Our results are in agreement with the findings of Kadiroğlu et al. (2018), who characterized registered chickpea varieties of Turkish origin based on functional properties and FTIR spectral characteristics.

\subsection{X-Ray diffraction analysis}

All samples (control, VE, and FR chickpeas) were subjected to XRD analysis for determination of crystallinity degree and to evaluate the effects of the vacuum expansion and frying on chickpeas crystallinity and results are shown in Figure 3. Raw (control) chickpea samples exhibited multiple peaks of variable intensities as compared to both VE and FR samples. Raw samples showed typical X-ray pattern with major diffraction peaks at $2 \theta=12.05^{\circ}, 15.09^{\circ}, 17.92^{\circ}$, and $24.00^{\circ}$ and minor diffraction peaks at $21.23^{\circ}$ and $26.03^{\circ}$. In the case of VE samples, the changes in crystalline structures were most significant, with diffraction peaks of considerable intensities at $16.48^{\circ}, 20.02^{\circ}$, and $22.37^{\circ}$. Similar peaks were demonstrated by FR samples at the same regions with considerably higher intensities as compared

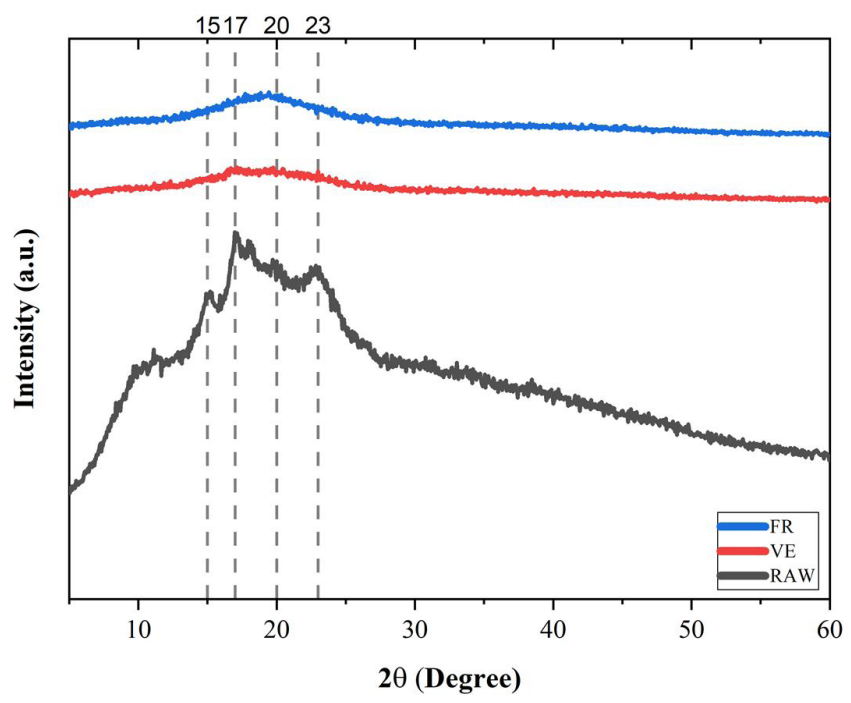

Figure 3. X-ray diffraction patterns of raw, VE and FR chickpea samples. 
to VE samples. The relative crystallinity of both VE and FR showed decreases in gelatinization enthalpies of starches in VE and FR chickpeas and intensity increases in FTIR bands, which demonstrated corresponding decreases in ordered structures and changes in crystal lattices of both VE and FR samples. $\mathrm{XRD}$ results further validated these tendencies. These results are in agreement with the those reported by Bashir \& Aggarwal (2017), whereby chickpea powder showed characteristic XRD peaks, and authors had reported the changes in peak intensities due to disruption of structural order, and relative crystallinity showed declining tendencies probably because of gelatinization phenomenon of chickpea starches.

\subsection{Thermal Gravimetric Analysis (TGA) of raw, VE and FR chickpeas}

The results of thermogravimetric analysis are demonstrated in Figure 4. The data obtained from TGA analysis was retrieved in the form of a smooth-curved plot, also known as the TGA curve, consisting of weight in percentage on the $y$-axis against temperature on the $\mathrm{x}$-axis. The thermal stability of all chickpea samples (raw, VE, and FR) were evaluated by analyzing TGA curves shown in Figure 4. The initial temperature, at which thermal degradation started, was described as the moisture loss step followed by the second weight loss step during TGA analysis. During the first step in TGA analysis, the rapid rise in ramp-heating temperature occurs, which caused increases in the sample's temperature. At $100^{\circ} \mathrm{C}$ temperature, the weight loss (shown as a weight percentage) was 93.69, 97.06, and $97.16 \%$ for raw, VE, and FR samples, respectively. This shows the stability of both VE and FR samples as compared to raw chickpea powder. Irrespective of sample type, gradual weight loss was observed with the corresponding rise in temperature. The weight loss was gradual in all samples until a temperature of $260^{\circ} \mathrm{C}$. The further rise in temperature led to a significant reduction in corresponding weight, and this weight decline was most significant for both control and VE

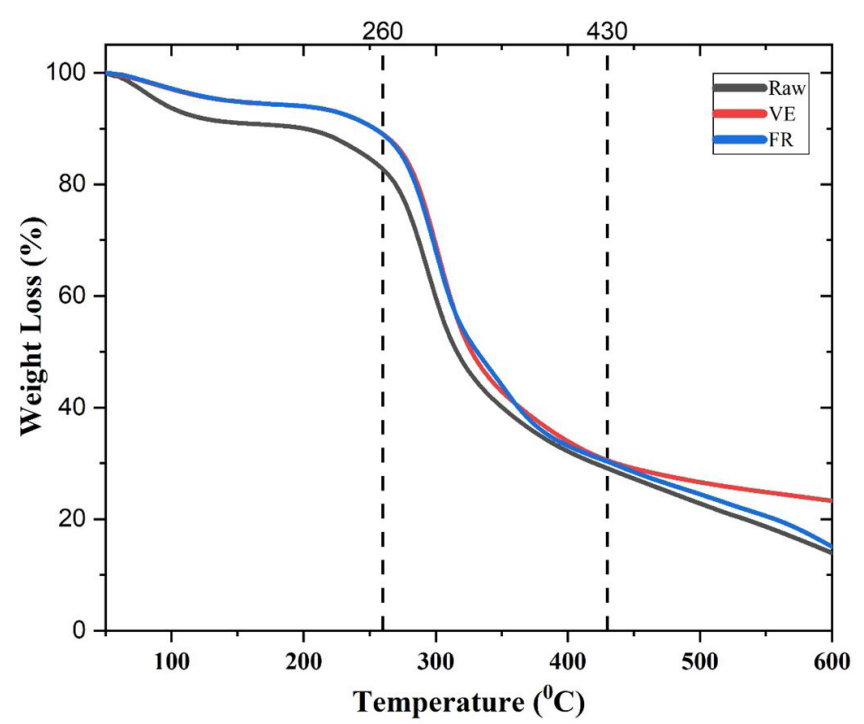

Figure 4. Comparative overview of TGA thermograms of raw, VE and FR chickpea samples. chickpea samples as compared to FR. FR samples showed a similar weight reduction tendency to that of raw samples. The final weight of VE samples was $23.28 \%$ as compared to raw and FR samples with weights of 13.92 and $15.05 \%$, respectively. A temperature increase above $430{ }^{\circ} \mathrm{C}$ did not affect VE samples' weight significantly, and the declining trend became smoother in comparison with raw and FR samples, which showed declining tendencies in a linear fashion. Weight loss in chickpea samples could be attributed to the phenomena of oxidative mass losses, organic matter desorption, and decomposition. Similar findings have been reported by Ricardi et al. (2018), who described weight loss tendency with rises in temperatures for chitosan samples. Similarly, chickpea protein concentrate was added to bread crumb prepared in various formulation with soy blend.

\subsection{Microstructural changes in raw, VE and FR chickpeas}

The focused beam of high-energy electrons was bombarded in SEM analysis on the surfaces of the chickpea samples to elucidate the external morphological features which revealed orientation of internal grain matrices and information about textural attributes and crystalline structures playing an important role in morphology determination. The micrographs of raw, VE, and FR samples are demonstrated in Figures 5a-i. In the case of raw grains, micrographs depicted granules of varied shape, mostly spherical, and few were relatively ovoid, and size heterogeneity in granules was also observed. The size and shape variations were more prominent at 500x (Figure 5b) and 1000x (Figure 5c) magnifications. The size was in the range of 22-31 $\mu \mathrm{m}$ (length) and 13-27 $\mu \mathrm{m}$ (width). The intricate network of protein bodies and matrix were also observed in chickpea grains, which existed in irregular or globular forms with clear discernment. The particle bodies existed between or on the surface of grains might also reflect the presence of inherent fiber components, starch granules, and minerals.

Conversely, micrographs of VE samples (Figures 5d-f) showed similar structural attributes to those observed in raw samples. Most grains showed smooth surfaces, and starch granules and protein bodies showed significant size reduction, and some were found in the fused state with VE treated grains, which might be due to the thermal effect of vacuum expansion, which caused slight surface fissures in some chickpea grains. Moreover, the majority of grains were found in the form of a smooth surface. The micrographs of FR samples also showed overall similar structural features to those observed for raw samples with certain differences. The protein bodies and starch granules were significantly reduced in FR samples due to the thermal effect rendered by frying pretreatment. Moreover, surface fissures were more evident in FR chickpea grains. The grain structure was modified from strictly ovoid to round or spherical forms. No prominent starch granules and protein bodies were visible in micrographs of FR samples, and grains were found in a flaked condition, which caused amorphousness in structural features and cracking of starch granules due to disintegration caused by vacuum expansion or frying as compared to raw chickpea samples. This might 

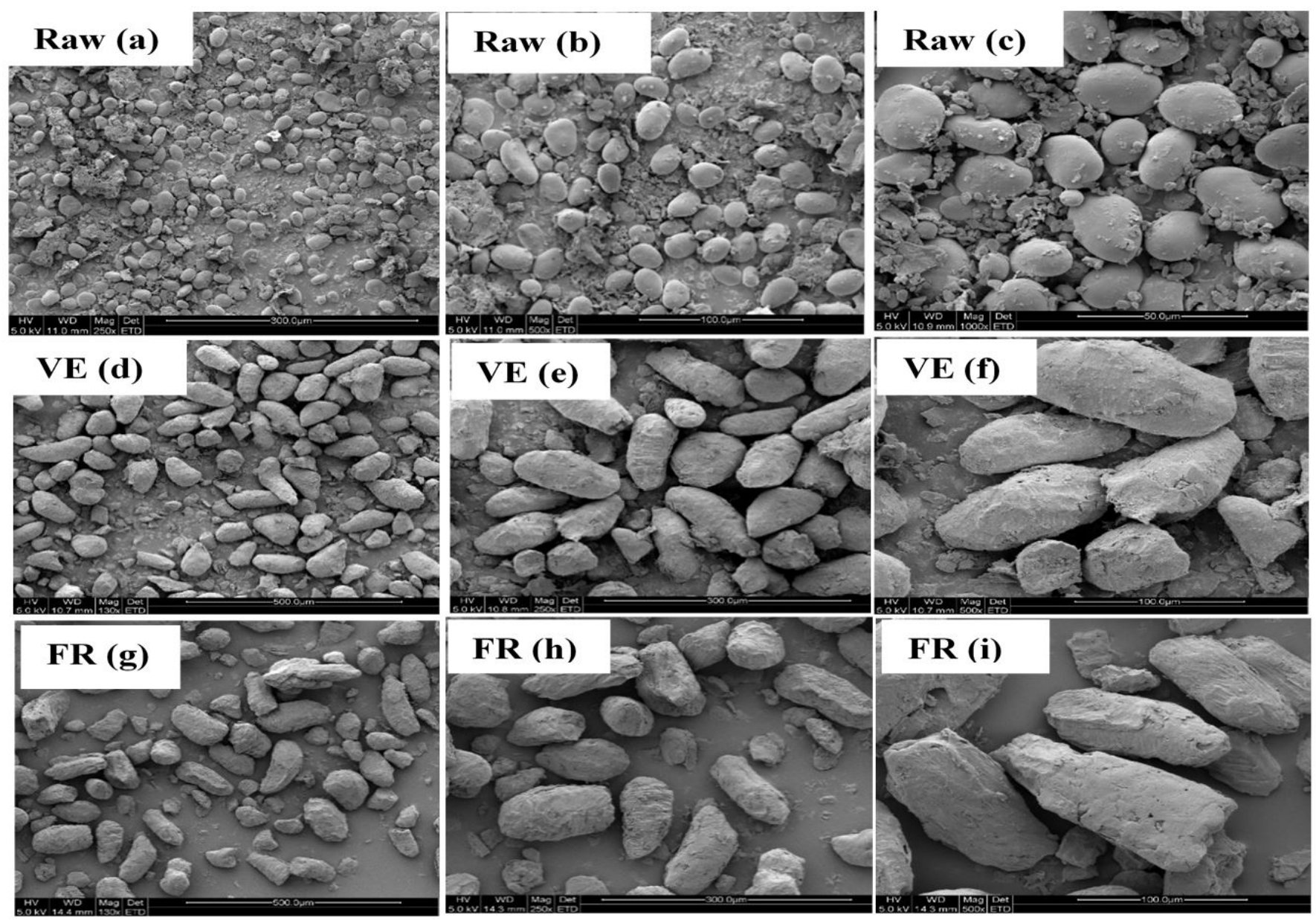

Figure 5. Scanning electron micrographs of raw (a-c), VE (d-f) and FR (g-i) chickpea grains.

be attributed to the pre-gelatinization effect due to frying pretreatment, which led to the formation of the cross-linked protein matrix and starch granules. The particle sizes of flaked and amorphous grains were more dependent on characteristic vacuum expansion and frying techniques. Similar findings have been reported by other researchers (Aguilera et al., 2009; Ma et al., 2011; Raza et al., 2019) who reported changes in particle sizes due to processing techniques, reduction in the starch granules, or absence of any starch granules in pulses grains subjected to cooking or milling. Moreover, researchers also reported the fissures, breakage, surface cracking due to disintegration and formation of cross-linked proteins in comparison with untreated (control) samples.

\subsection{The viscosity of raw, VE and FR chickpeas}

All samples (raw, VE, and FR) were evaluated for their viscosity parameters (shear stress, shear rate, and viscosity), and results are demonstrated in Figure 6a-i. The first parameter of the viscosity profile was shear stress. The degree of friction offered by the material is usually in direct proportion with the required force, and this force is termed as the shear stress. According to Newtonian fluid laws, the shear rate and shear stress, at any given temperature, are the same (in a linear relationship) without any significant difference. Moreover, shear viscosity remains invariably the same (constant) with corresponding rises in shear rate and shearing time. Any fluid with deviation in behavior from this criterion is known as the Non-Newtonian fluid. In the case of raw (control) samples, the sample exhibited the non-Newtonian fluid behavior with corresponding rises in step time and temperature up to $350 \mathrm{~s}$ and $54.13{ }^{\circ} \mathrm{C}$, respectively (Figure 6a, d, g). Further rises in both shearing time and temperature led to fluid kinetics according to Newtonian fluid behavior. The mean values of shear stress and shear rates were $20 \mathrm{~Pa}$ and $484.72 \mathrm{~s}^{-1}$, respectively. In the case of viscosity, raw samples showed a non-linear relationship. Viscosity showed a gradual decline with corresponding rises in shear rate until step time of $350 \mathrm{~s}$ and temperature of $54.13{ }^{\circ} \mathrm{C}$, whereas the rise in viscosity was observed after increases in step time and temperature up to the maximum value of $36.05 \mathrm{~Pa}$.s with an inverse relationship with shear rate, and the recorded shear rate was the lowest at this point $\left(0.56 \mathrm{~s}^{-1}\right)$. Raw samples showed a mean viscosity of $39.68 \mathrm{~Pa} . \mathrm{s}$ (Figure $6 \mathrm{~g}$ ). The Non-Newtonian behavior of raw chickpea samples suggested that operational viscometer parameters exerted significant $(p<0.05)$ influence on viscous profiles of raw samples, and raw samples showed pseudo-plasticity with respect to viscosity owing to the applied shearing time and thermal effect. As compared to control, VE samples 

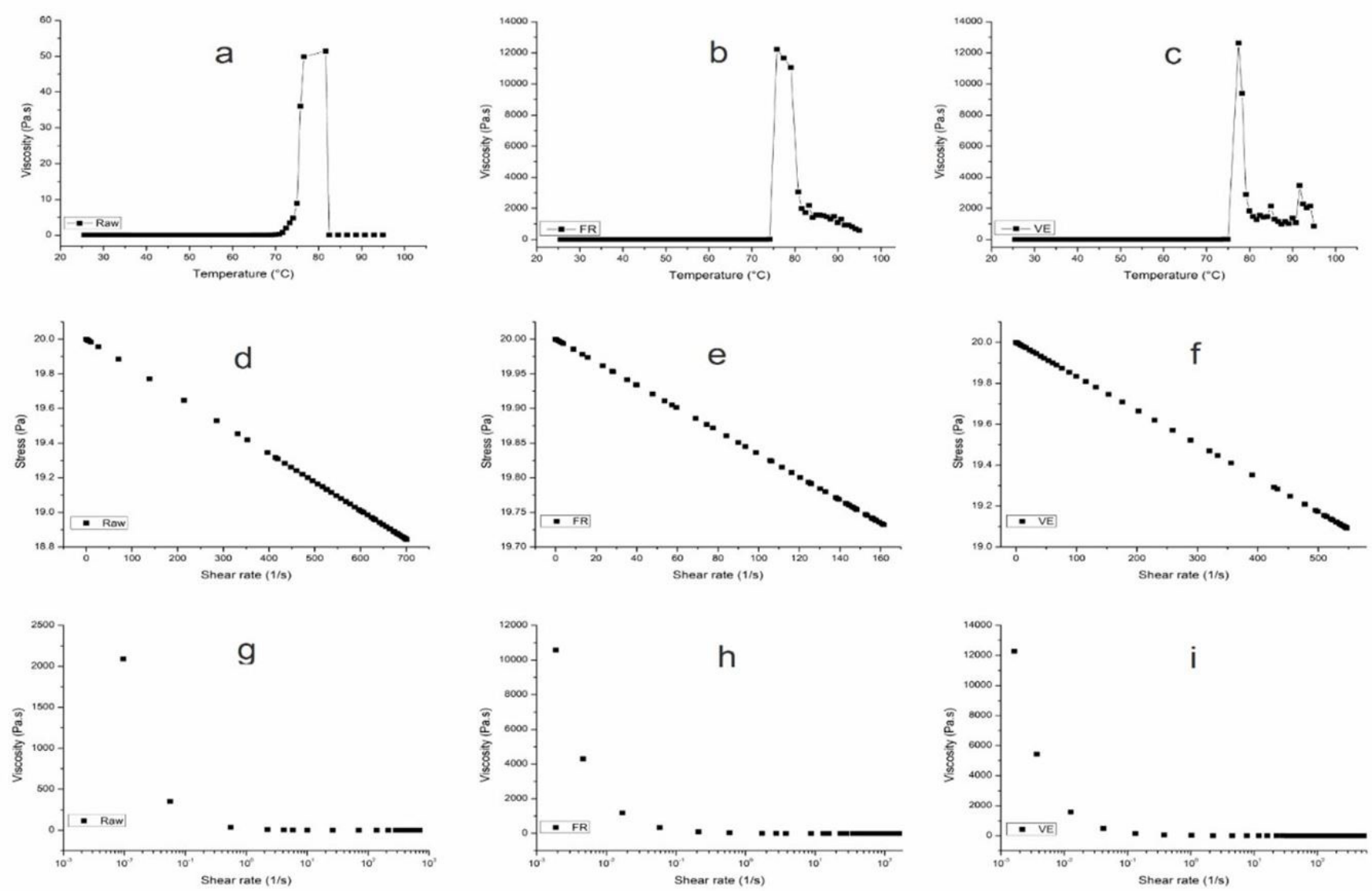

Figure 6. Viscosity profiles and tendencies of samples under applied stress, shear stress, and temperature: Raw (a, d, g), VE (c, f, i), and FR (b, e, h).

exhibited the inverse tendency, and shear rate showed an inverse relationship with velocity up to step time of $140.01 \mathrm{~s}$ and temperature of $36.58{ }^{\circ} \mathrm{C}$ (Figures $6 \mathrm{c}, \mathrm{f}, \mathrm{i}$ ). This implied that VE modified the viscous properties, and pseudo-elasticity was observed to a lower extent in VE treated chickpeas. After step time of $140.01 \mathrm{~s}$ and temperature of $36.58^{\circ} \mathrm{C}$, viscosity started increasing with corresponding decreases in shear rate and exhibited the shear-thinning behavior, which is also referred as the dilatancy (Figure 6f). This dilatancy is usually observed in the case of food mixtures, aqueous corn starch, candy compounds, and slurries as well. This dilatancy might be caused by the pre-gelatinization of starches and fused complexes with protein bodies due to the thermal effect of vacuum expansion in chickpeas and led to a massive rise in viscosity. VE samples showed a mean viscosity of 339.21 Pa.s. that was quite higher as compared to control samples. In the case of FR samples, viscosity showed a similar tendency of inverse relationship with the shear rate as that was observed in VE samples. However, the increase in viscosity with corresponding decreases in shear rate was steadier and more gradual as compared to VE and control samples. Shear-thinning (pseudo-plasticity) in FR chickpeas samples was observed until a step time of $220 \mathrm{~s}$ and a temperature of $43.30^{\circ} \mathrm{C}$ (Figures $6 \mathrm{~b}, \mathrm{e}, \mathrm{h}$ ). The, further rises in temperature and shearing time caused dilatancy (shear-thickening) in FR chickpea samples, and viscosity exhibited the increasing tendency and mean viscosity of the FR samples was $271.47 \mathrm{~Pa} . \mathrm{s}$ (Figure 6h). A comparative overview of mean values of viscosity revealed that VE samples were the most viscous, followed by FR and raw chickpea samples. A high degree of viscosity is indicative of the tight packing and enhanced cross-linking of inherent molecules, and the same was observed for VE samples owing to the maximum resistance offered against the deformation and phenomenon of vacuum expansion. Our results are in agreement with the findings of Kaur \& Singh (2005), who reported temperature-dependent increases in the viscosity of Kabuli and Desi chickpea flours and attributed this rise in viscosity to the gelatinization phenomenon along with moisture removal from grains. In another report by Singh et al. (2004), the authors reported rise and fall in viscosity associated to the swelling power of the chickpeas starches and declared chickpea flour paste to exhibit the thermal stability which makes it suitable for industrial applications without degradation and disruptive swelling of the legume starches. In a recent report by Guzmán et al. (2010), the authors have reported the shear-thinning phenomenon for a high degree of viscoelastic behavior owing to the gelatinization of starch molecules, and an increase in temperature led to the rise in frequency and molecular motion which resultantly enhanced the viscous flow and viscoelastic behavior of maize proteins. 


\section{Conclusion}

Chickpea, as a leguminous crop, is popular worldwide and consumed as a roasted snack. However, hard textural attributes of chickpea necessitated the employment of specialized pretreatment prior to the roasting process. Intensification of Vaporization by Decompression to the Vacuum (IVDV) as vacuum expansion technique was utilized in order to improve and preserve the nutritional, textural and structural properties of chickpeas in this study and compared with the raw and fried samples to obtain good vacuum expansion without any detrimental effects on the nutritional and color properties. It was clearly demonstrated that FR treatment had a significant influence and led to decreases in a light color of chickpeas, while VE did not cause a significant effect on the lightness, and the slightly decreasing tendency was observed in VE chickpeas. Raw and VE showed a mixed combination of green and red colors, while the degree of greenness showed a high tendency in the case of control samples. FR also caused a reduction in $\mathrm{a}_{\mathrm{w}}$, but the declining tendency was more significant in VE chickpeas comparatively. In comparison with control, the VE and FR showed quite low $\mathrm{a}_{\mathrm{w}}$ values. The FR treatment was not so influential in causing the decreases of phenolic compounds, while the $\mathrm{C}=\mathrm{O}$ stretching of the VE chickpeas was lesser in magnitude as compared to control, which was evident from the stability of functional groups related to phenolic compounds even after exposure to the vacuum expansion pretreatment. The relative crystallinity of both VE and FR showed decreasing tendencies owing to decreases in gelatinization enthalpy of starches in VE and FR chickpeas and an increase in bands of FTIR spectra, which demonstrated corresponding decreases in ordered structures and changes in the crystal lattices of both VE and FR samples. TGA analysis showed that the rise in temperature led to a significant reduction in corresponding weight, and this weight decline was most significant for both control and VE chickpea samples as compared to FR samples. The surface fissures were more evident in FR chickpea grains. The grains structure was modified from strictly ovoid to rounded and spherical forms. A high degree of viscosity is indicative of the tight packing and enhanced cross-linking of inherent molecules, and the same was observed for VE samples owing to the phenomenon of vacuum expansion and maximum resistance offered against deformation.

\section{Acknowledgements}

This study was supported by the grants from the State Key Research and Development Plan (No. 2017YFD0400200), the Key Research and Development Program of Jiangsu Province (BE2017374) and Jiangsu province "Collaborative Innovation Center for Food Safety and Quality Control” industry development program.

\section{References}

Aguilera, Y., Martín-Cabrejas, M. A., Benítez, V., Mollá, E., LópezAndréu, F. J., \& Esteban, R. M. (2009). Changes in carbohydrate fraction during dehydration process of common legumes. Journal of Food Composition and Analysis, 22(7-8), 678-683. http://dx.doi. org/10.1016/j.jfca.2009.02.012.
American Association of Cereal Chemist - AACC. (2000). Approved methods of the American association of cereal chemists. St. Paul: AACC.

Bashir, K., \& Aggarwal, M. (2017). Physicochemical, thermal and functional properties of gamma irradiated chickpea starch. International Journal of Biological Macromolecules, 97, 426-433. http://dx.doi.org/10.1016/j.ijbiomac.2017.01.025. PMid:28069349.

D’Archivio, M., Filesi, C., Varì, R., Scazzocchio, B., \& Masella, R. (2010). Bioavailability of the polyphenols: Status and controversies. International Journal of Molecular Sciences, 11(4), 1321-1342. http:// dx.doi.org/10.3390/ijms11041321. PMid:20480022.

Guzmán, A. Q., Jaramillo Flores, M. E., Feria, J. S., Méndez Montealvo, M. G., \& Wang, Y.-J. (2010). Effects of polymerization changes in maize proteins during nixtamalization on the thermal and viscoelastic properties of masa in model systems. Journal of Cereal Science, 52(2), 152-160. http://dx.doi.org/10.1016/j.jcs.2010.04.007.

Kadiroğlu, P., Aydemir, L. Y., \& Akcakaya, F. G. (2018). Prediction of functional properties of registered chickpea samples using FT-IR spectroscopy and chemometrics. $L W T, 93,463-469$. http://dx.doi. org/10.1016/j.lwt.2018.03.080.

Kaur, M., \& Singh, N. (2005). Studies on functional, thermal and pasting properties of flours from different chickpea (Cicer arietinum L.) cultivars. Food Chemistry, 91(3), 403-411. http://dx.doi.org/10.1016/j. foodchem.2004.06.015.

Ladjal-Ettoumi, Y., Boudries, H., Chibane, M., \& Romero, A. (2016). Pea, chickpea and lentil protein isolates: Physicochemical characterization and emulsifying properties. Food Biophysics, 11(1), 43-51. http:// dx.doi.org/10.1007/s11483-015-9411-6.

Louka, N., \& Allaf, K. (2004). Expansion ratio and color improvement of dried vegetables texturized by a new process "controlled sudden decompression to the vacuum": application to potatoes, carrots and onions. Journal of Food Engineering, 65(2), 233-243. http://dx.doi. org/10.1016/j.jfoodeng.2004.01.020.

Ma, Z., Boye, J. I., Simpson, B. K., Prasher, S. O., Monpetit, D., \& Malcolmson, L. (2011). Thermal processing effects on the functional properties and microstructure of lentil, chickpea, and pea flours. Food Research International, 44(8), 2534-2544. http://dx.doi.org/10.1016/j. foodres.2010.12.017.

Mrad, R., Debs, E., Saliba, R., Maroun, R. G., \& Louka, N. (2014). Multiple optimization of chemical and textural properties of roasted expanded purple maize using response surface methodology. Journal of Cereal Science, 60(2), 397-405. http://dx.doi.org/10.1016/j. jcs.2014.05.005.

Mrad, R., El Rammouz, R., Maroun, R. G., \& Louka, N. (2015). Effect of intensification of vaporization by decompression to the vacuum as a pretreatment for roasting australian chickpea: Multiple optimization by response surface methodology of chemical, textural and color parameters. Journal of Food Quality, 38(2), 139-152. http://dx.doi. org/10.1111/jfq.12128.

Petitot, M., Barron, C., Morel, M. H., \& Micard, V. (2010). Impact of legume flour addition on pasta structure: Consequences on its in vitro starch digestibility. Food Biophysics, 5(4), 284-299. http:// dx.doi.org/10.1007/s11483-010-9170-3.

Raza, H., Ameer, K., Zaaboul, F., Sharif, H. R., Ali, B., Shoaib, M., Akhtar W., \& Zhang, L. (2019). Effects of ball-milling on physicochemical, thermal and functional properties of extruded chickpea (Cicer arietinum L.) powder. CYTA: Journal of Food, 17(1), 563-573. http:// dx.doi.org/10.1080/19476337.2019.1617352.

Ricardi, N. C., Menezes, E. W., Valmir Benvenutti, E., Natividade Schöffer, J., Hackenhaar, C. R., Hertz, P. F., \& Costa, T. M. H. (2018). Highly stable novel silica/chitosan support for $\beta$-galactosidase immobilization 
for application in dairy technology. Food Chemistry, 246, 343-350. http://dx.doi.org/10.1016/j.foodchem.2017.11.026. PMid:29291859.

Shokrollahi Yancheshmeh, B., Mohebbi, M., Varidi, M., Razavi, S. M., \& Ansarifar, E. (2018). Performance of lentil and chickpea flour in deep-fried crust model (DFCM): Oil barrier and crispy properties. Journal of Food Measurement and Characterization, 13(1), 296-304. http://dx.doi.org/10.1007/s11694-018-9944-8.

Singh, N., Singh Sandhu, K., \& Kaur, M. (2004). Characterization of starches separated from Indian chickpea (Cicer arietinum L.) cultivars. Journal of Food Engineering, 63(4), 441-449. http://dx.doi. org/10.1016/j.jfoodeng.2003.09.003.

Ullah, R. (2014). Effect of water activity and storage time on the proximate composition of two chickpea cultivars. European Journal of Biology and Medical Science Research, 2(2), 25-36.

Zhong, L., Fang, Z., Wahlqvist, M. L., Wu, G., Hodgson, J. M., \& Johnson, S. K. (2018). Seed coats of pulses as a food ingredient: characterization, processing, and applications. Trends in Food Science \& Technology, 80, 35-42. http://dx.doi.org/10.1016/j.tifs.2018.07.021. 